\title{
SOCIEDADE DE CONTROLE E REDES SOCIAIS NA INTERNET: \#SAÚDE E \#CORPO NO INSTAGRAM
}

\author{
SOCIETY OF CONTROL AND SOCIAL MEDIA: \#HEALTH AND \#BODY \\ ON INSTAGRAM C
}

SOCIEDAD DE CONTROL Y REDES SOCIALES EN LA INTERNET: \#SALUD Y\#CUERPO EN INSTAGRAM C P

doi' https://doi.org/10.22456/1982-8918.100688

Angélica Teixeira da Silva Leitzke*<leitzke.angelica@gmail.com>

Luiz Carlos Rigo*<rigoperini@gmail.com>

*Universidade Federal de Pelotas. Pelotas, RS, Brasil.

Resumo: O objetivo deste artigo é analisar texto e imagem de publicações na rede social Instagram, com as hashtags \#saúde e \#corpo, a partir da noção deleuzeana de sociedade de controle. Para a coleta, utilizou-se o site Netlytic e, para a seleção dos dados, o software LibreOffice Calc. A metodologia consiste em uma análise enunciativa de perspectiva foucaultiana. Os resultados assinalam a presença de práticas que remetem às técnicas de confissão, de intervenção e de manipulação do corpo e às estratégias de controle para produção da saúde a partir da produção de verdades. Esses são indícios da operacionalização dos atuais mecanismos de vigilância da saúde e das estratégias de governamentalidade na sociedade de controle.

Palavras chave: Governo eletrônico. Controle da População. Saúde. Redes sociais online.

Recebido em: 27-02-2020 Aprovado em: 25-06-2020 Publicado em: 20-08-2020

\section{(c) (1) ()}

Este é um artigo publicado sob a licença Creative Commons atribuição Não Comercial 4.0 (CC BY-NC 4.0).

eISSN: 1982-8918 


\section{INTRODUÇÃO}

Ocorre, na contemporaneidade, uma revolução tecnocientífica e eletrônica, que eleva a Internet a uma das mais surpreendentes mídias já desenvolvidas (ANTOUN, 2008). As influências dessa revolução vão além das mudanças nos modelos de comunicação, refletindo o que Deleuze (1992) apresenta como indícios da emergência de uma sociedade de controle: uma nova configuração social, exercida a partir de um poder constante e de uma comunicação rápida e contínua.

As condições de emergência da sociedade de controle, além de no desenvolvimento tecnocientífico, estão no êxito das estratégias disciplinares e na crise das instituições de confinamento, ambas típicas da anterior sociedade disciplinar, desenvolvida desde meados do século XVII (DELEUZE, 1992; FOUCAULT, 2007).

$\mathrm{Na}$ sociedade disciplinar, o modelo de vigilância é executado a partir do sequestro dos corpos para dentro das instituições de confinamento - fábricas, hospitais, exércitos, escolas -, onde são classificados e tornam-se objeto para a produção de novos saberes. Com o aperfeiçoamento desse processo - sequestro, classificação e produção de saberes -, passa-se do homem-corpo ao homemespécie; de uma anátomo-política do corpo a uma biopolítica ${ }^{1}$ da população, o que ocasiona um refinamento das estratégias de governamentalidade ${ }^{2}$ (FOUCAULT, 2007; 2008a; 2008b; 2011; 2016).

Segundo Foucault, fazer viver uma população é o grande problema do governo na sociedade disciplinar. Desse modo, é exercido um (bio)poder regulamentador sobre o corpo - tido enquanto realidade biopolítica - objetivando a correção das normas de conduta e dos desvios de normalidade ${ }^{3}$, propiciando a produção de verdades e também de subjetividades dóceis, oriundas de diferentes tecnologias de si, implicando práticas de saúde (FOUCAULT, 1999a; 2008a; 2011; 2016).

No entanto, Foucault (2006) apontava uma eventual separação do modelo de sociedade de disciplina. Ao tratar dos indícios dessa separação, Deleuze (1992) identifica a emergência da sociedade de controle, um modelo em que a vigilância é executada a partir da regulação das informações. Para ele, o computador seria a máquina que melhor representaria as novas formas de exercício do poder.

Com a evolução tecnológica das máquinas de computador, emerge o ciberespaço, um "[...] espaço de comunicação navegável e transparente, centrado na informação" (LÉVY, 1999, p. 43), que acopla todos os computadores conectados através da Internet. A Internet, articulada especialmente a partir de plataformas de relacionamentos interpessoais e aplicativos em rede, aperfeiçoados pela inteligência

1 "[...] maneira como se procurou, desde o século XVIII, racionalizar os problemas postos à prática governamental pelos fenômenos próprios de um conjunto de viventes constituídos em população: saúde, higiene, natalidade, longevidade, raças [...]" (FOUCAULT, 2008b, p. 431).

2 Conjunto de instituições, técnicas e relações que propiciam o exercício de um poder chamado governo, exercido sobre a população, a partir, primordialmente, da economia política como forma de saber e dos dispositivos de segurança enquanto técnica fundamental - uma certa convergência entre as técnicas de dominação e as tecnologias de si (FOUCAULT, 2006; 2011; 2016).

3 A questão do normal e do patológico, em Foucault, relaciona-se, em certa medida, às concepções de Canguilhem (2010), para o qual a anomalia, o anormal e o patológico não existem por si só, sendo apenas expressões de vida possíveis. 
coletiva (O'REILLY, 2005), potencializa a produção contemporânea de saberes. Suas características multimodais, relacionais e de rede (LÉVY, 1993) ${ }^{4}$ alicerçam uma coparticipação criativa de interações mútuas entre os usuários (PRIMO, 2000), principalmente nas plataformas de redes sociais.

As redes sociais, agrupamentos construídos justamente pela interação mútua entre os sujeitos, seja online ou offline, constituem o que Recuero, Bastos e Zago (2015, p. 23) identificam como "[...] estrutura fundamental para a sociedade". Na Internet, essas redes operacionalizam-se em plataformas, tornando suas conexões mais estáveis e possibilitando o registro e extração de uma quantidade maciça de dados, o que converte os espaços virtuais em relevantes campos de pesquisa (RECUERO; BASTOS; ZAGO, 2015).

Dentre as redes sociais de destaque na Internet, tem-se o Instagram, uma plataforma de publicação de imagens e vídeos com cerca de 66 milhões de usuários no Brasil, segundo país com mais usuários no mundo ${ }^{5}$. Normalmente acessado via smartphone, possui conectividade com outras plataformas e permite a publicação de legendas com a adição de hashtags (\#), que se comportam como hiperlinks para buscabilidade.

Considerando o potencial de abrangência e produtividade do Instagram (SILVA et al., 2013), é relevante observar suas relações discursivas sobre saúde e corpo. A temática da saúde no campo midiático, na perspectiva foucaultiana, já foi objeto de outros estudos (FRAGA, 2006; OLIVEIRA et al., 2010; GOMES; CAMINHA, 2016; LEITZKE; RIGO; KNUTH, 2020), inclusive de pesquisas sobre o Instagram (JACOB, 2014; FERNANDES, 2016), mas são raros os estudos que abordam a mesma temática a partir da perspectiva deleuziana de sociedade de controle. Nesse sentido, este artigo objetivou analisar texto e imagem de publicações do Instagram com as hashtags \#saúde e \#corpo, discutindo indícios da operacionalização dos mecanismos de governamentalidade no contexto da sociedade de controle.

\section{CAMINHOS TEÓRICO-METODOLÓGICOS}

O corpus empírico desta pesquisa constitui-se de 52 publicações do Instagram. Para coleta dos dados, utilizou-se a ferramenta de extração via API ${ }^{6} \mathrm{Net}$ ytic ${ }^{7}$.

Durante quatro semanas, em dias alternados ${ }^{8}$, foram extraídas 24.178 postagens, dentre publicações e comentários, a partir da hashtag \#saúde. Os dados (data e hora, perfil, texto e link para acesso das postagens) referentes a cada dia foram agrupados em um único arquivo de planilha eletrônica. Posteriormente, através da ferramenta de filtro padrão do LibreOffice Calc, selecionaram-se apenas postagens

\footnotetext{
4 Representações diversas relativas a uma mesma mensagem, remodelando sentidos diversificados (LÉVY, 1993). 5 AGRELA, Lucas. Estes são os dez países que mais usam o Instagram. Exame, 12 mai. 2019. Disponível em: https://exame.abril.com.br/tecnologia/estes-sao-os-dez-paises-que-mais-usam-o-instagram/. Acesso em: 23 jul. 2020. 6 Application Programming Interface, "[...] comandos que permitem a usuários e aplicativos se comunicarem com os sites e requisitarem dados hospedados em seus servidores" (ALVES, 2016, p. 74).

7 NETLYTIC. Disponível em: https://netlytic.org/. Acesso em: 23 jul. 2020.

8 Os dias de coleta foram escolhidos aleatoriamente, com uma frequência de, ao menos, dois dias por semana, no período compreendido entre 22/02/2018 e 25/03/2018.
} 
que continham concomitantemente as hashtags \#saúde e \#corpo ${ }^{9}$, restando 281 . Em um terceiro momento, as 281 postagens foram acessadas no Instagram e "printadas" para análise. Para esta pesquisa, foram selecionadas apenas as publicações sem caráter de venda de produto ou prestação de serviço, desconsiderando-se comentários e vídeos, restando as 52 publicações analisadas.

A coleta seguiu a Política de dados do Instagram $^{10}$, e, em observância às recomendações do comitê de trabalho de ética da Association of Internet Researchers $(\text { AolR })^{11}$, não foram divulgados links ou imagens analisadas.

O tratamento dos dados, enquanto fontes históricas, privilegia uma análise enunciativa a partir dos pressupostos foucaultianos. Percebe-se o enunciado enquanto conjunto de focos de relações de força visíveis, ao mesmo tempo que ocultos. Sua transversalidade garante sua irredutibilidade a um mero contexto, tendo relações com quem o produz ou reproduz e com os espaços ou instituições onde se articula (FOUCAULT, 1996; 1999b; 2006; DELEUZE, 2005).

Consideram-se as diagonais que interligam as práticas discursivas e não discursivas através da análise das relações discursivas entre as duas práticas, identificando seus sistemas de formação e seus processos de saber-poder imbricados a regimes de verdade, suas condições de possibilidade de existência, seus mecanismos de manifestação e materialidade, procedimentos e os sujeitos que Ihes operam, testemunham ou mesmo lhes são objeto, fazendo aparecer as múltiplas formas de constituição da realidade, seus efeitos e possibilidades de resistência (FOUCAULT, 2006; 2011; DELEUZE, 2005).

Busca-se "[...] recolocar o regime de produção do verdadeiro e do falso no coração da análise histórica e da crítica política" (FOUCAULT, 2006, p. 343), delineando quais as formas de produção de subjetividade relativas aos jogos de verdade de um biopoder, que constitui as atuais relações de governo da vida e da saúde na sociedade de controle.

\section{3 \#SAÚDE E \#CORPO NO INSTAGRAM: OPERACIONALIZAÇÃO DE UMA SOCIEDADE DE CONTROLE}

As publicações analisadas trazem imagens de homens e mulheres durante ou após a realização de atividades físicas variadas, em muitas, exibindo o que se apresenta como resultados de rotinas de treinos eficientes. Há também imagens de pratos e receitas, dicas de saúde e beleza, bem como textos de incentivo.

Estimuladas pelas características da plataforma, estratégias discursivas de confissão se destacam. Os usuários "postam" textos em que confessam como estão se saindo em suas rotinas de exercícios ou de dieta, exibindo seus pratos e corpos como comprovação de seu empenho e êxito.

9 Consideraram-se todas as variações das hashtags. A opção por delimitar o estudo deu-se a partir da perspectiva teórica assumida, entendendo o corpo enquanto realidade biopolítica, em que se inicia a operacionalização do controle, pois "foi no biológico, no somático, no corporal que, antes de tudo, investiu a sociedade capitalista" (FOUCAULT, 2016, p. 144).

10 INSTAGRAM. Política de dados. c2020. Disponível em: https://help.instagram.com/519522125107875. Acesso em: 23 jul. 2020.

11 ASSOCIATION OF INTERNET RESEARCHERS. Ethics. c2020. Disponível em: https://aoir.org/ethics/. Acesso em: 23 jul. 2020. 
Neste sentido, um usuário confessa, apresentando um prato com torradas e ovos: "CAFÉ DA MANHÃ HOJE COM DOIS OVINHOS + 1 FATIA DE PÃOZINHO INTEGRAL + CAFEZINHO COM LEITE" (13/03/2018); declara, ainda, a partir do uso de hashtags, seu foco em uma "\#reeducacaoalimentar", exibindo o que chama de "\#diariofitsemneurose \#DIETASEMNEURA", posta em prática por "\#amorproprio".

Outro usuário exibe imagens de si de frente e de perfil, confessando sua "\#ResoluçãoDeAnoNovo", vinculada a uma "\#ReeducaçãoAlimentar" e associada ao "\#treino": "Peso: 63 Tórax: 92 Braço: 28 Cintura: 83 Quadril: 92 Começo de \#Março, pouca coisa mudou de Fevereiro pra cá [...] E claro, preciso maneirar nas comidas gordurosas à noite, e aproveitar os outros dias sem aula pra usar o \#freeletics ${ }^{12}$. Pode não aparecer mas vejo mudanças na região abdominal, amém" (13/03/2018).

Uma usuária, exibindo uma selfie, confessa, com o uso de hashtags, seus interesses em "\#bike" e "\#spinning" (23/02/2018). Há, também, outra usuária que utiliza uma selfie de corpo inteiro para confessar que pratica "\#caminhada", salientando: "\#entãovamos \#néh" (21/03/2018). Ainda mais uma usuária exibe em uma selfie mostrando seu corpo usando um biquíni, declarando obediência a hábitos de "\#vidasaudavel", como "\#caminhada" e "\#boaalimentação" (25/03/2018).

Destaca-se outra usurária, que confessa seu processo de modificação corporal, exibindo uma imagem de antes e depois de suas "\#mudancasdehabito" e aderência a programas de "\#jejumintermitente" e "\#projetofitness" (21/03/2018). Mais uma publica uma selfie na academia após o treino: "mesmo com uma preguiça enorme, tomei meu termogênico e fui para a academia" (23/02/2018). Neste sentido, ainda outra usuária publica uma foto executando um exercício de corda naval e confessa: "Morreni" (13/03/2018), salientando que "\#tapago" o "\#funcionaldodia".

Percebem-se indícios de que a confissão se operacionaliza, na atualidade, como uma técnica de subjetivação e estratégia de governamentalidade, noção já anunciada por Foucault (2016) ao traçar uma genealogia da obediência. As práticas confessionais, típicas da moralidade cristã, constituíam, na sociedade disciplinar, um importante dispositivo para o exercício da governamentalidade. A submissão e a obediência partem diretamente da obrigatoriedade de se dizer a verdade sobre si mesmo, desde seus pecados até seus desejos, traçando enunciados sobre si. Para um efetivo governo dos vivos, é necessária uma junção eficiente entre os dispositivos de regulamentação e as tecnologias de si, estas últimas desenvolvidas principalmente a partir da confissão, implicando diferentes modos de subjetivação (FOUCAULT, 1999a; 2008a; 2011).

$\mathrm{Na}$ atual sociedade de controle, ainda que em um contexto diferenciado, os indícios apontam que os sujeitos seguem instigados a falarem sobre si e a confessarem, agora nas redes sociais, seus modos de ser e estar. A permanência das técnicas de confissão como estratégias de governo assinala que, de forma um pouco diferente do que pressupunha Deleuze (1992), a crise das instituições de confinamento não as levou à extinção, mas, antes, as dissolveu nas incontáveis estrias da aparentemente lisa sociedade de controle. As estratégias de disciplinamento e regulamentação, antes centradas nos limites das instituições, invadem os espaços públicos. O borramento 12 FREELETICS. c2020. Disponível em: https://www.freeletics.com/pt/. Acesso em: 23 jul. 2020. 
entre as fronteiras do público e do privado produz novos saberes e novos modos de subjetivação e de assujeitamento no século XXI (HARDT, 2000).

Essa perspectiva corrobora a percepção de Recuero, Bastos e Zago (2015) acerca da atuação das mídias sociais como traduções da esfera pública. Os discursos ali produzidos pelos sujeitos, ainda que de caráter confessional, evidenciam o que constitui a "opinião pública", contexto que propicia a emergência da exposição do Eu. É necessário contar a todos como Eu me visto, como Eu me alimento, exibir aquilo que Eu gosto e consumo, em outras palavras, confessar quem Eu sou para assim poder vir a Ser. A confissão se relaciona diretamente com o "Show do Eu" (SIBILIA, 2008).

Nas publicações analisadas, os corpos dos usuários são exibidos como "prova" para comprovação de seus hábitos saudáveis, o que expressa as marcas do processo histórico de intervenção e manipulação do corpo. Os corpos, que na segunda metade do século XX já estão suficientemente disciplinados, alinhados, modelados e classificados (FOUCAULT, 2007), passam a ser anunciados como referência, e, a partir do século XXI, com a emergência da sociedade de controle, virtualizam-se e aumentam sua visibilidade: corpos virtuais que produzem efeitos de realidade, confessando estratégias de saúde e exibindo modelos e padrões.

Corroborando essa compreensão, destacam-se mais duas publicações: um usuário que posta uma selfie durante a prática de exercícios: "Comece a cuidar mais de você! Faça atividades físicas, sua saúde agradece!" (22/02/2018), e uma imagem de um homem realizando uma atividade, acompanhada da mensagem: "Meu treino me leva a ter um corpo mais eficiente e mais forte para minhas atividades esportivas e para minha vida" (07/03/2018).

Intervenções e investimentos sobre o corpo desenvolveram-se a partir de um ideário de saúde e beleza referendados em saberes que emergiram no século XX, como é o caso, por exemplo, do cálculo do IMC (índice de massa corporal) (VIGARELLO, 2006; SANTOLIN; RIGO, 2015). Sant'Anna (2014, p. 16) destaca que "[...] a transformação do embelezamento em gênero de primeira necessidade marcou profundamente o século XX", produzindo estratégias de manipulação do corpo, subsidiadas por um discurso de saúde.

As relações entre corpo, saúde e beleza expressas na atualidade e percebidas também nas publicações extraídas constroem-se em conjunto com a ascensão das práticas fitness, de ginásticas e de dietas. No Brasil, principalmente a partir da década de 1980, tais práticas ganharam força junto à promoção de imagens de corpos atléticos, jovens e desejáveis (SANT'ANNA, 2014). Essa tendência, por vezes, serviu de justificativa para a aparição de discursos que desqualificam e até patologizam o corpo gordo (SANTOLIN; RIGO, 2015). Principalmente a partir da segunda metade do século XX, "a magreza encarna o novo ideal de beleza, e a gordura é associada à doença [...]" (ANDRADE, 2003, p. 126, grifos do autor).

Expresso nas publicações e endereçado aos possíveis seguidores, o chamamento à "\#boaforma" ${ }^{13}$ carrega regimes de verdades vinculados a determinadas

\footnotetext{
13 Aqui utiliza-se a expressão "boa forma" em seu formato de hashtag (\#), tal como aparece nos excertos analisados. Em outros momentos do texto as hashtags também são utilizadas como recurso de linguagem para enfatizar as expressões encontradas no decorrer da análise.
} 
formações discursivas normativas e normalizadoras acerca da responsabilização dos sujeitos sobre sua saúde.

Isso pode ser observado, por exemplo, na publicação de uma usuária que exibe seu corpo magro e declara: "Se amar faz bem, Mas se cuidar também. [...] Hoje quero estimular você a se amar!" e complementa com hashtags como "\#sejaFeliz", "\#reaja" e "\#alimentaçãosaudavel", "\#corpoperfeito", "\#emagrecimento", "\#barrigachapada" e "\#barriganegativa" (21/03/2018). Ainda outro exemplo é a publicação de um usuário, em que se observa a seguinte legenda na imagem "A regra é simples... ou você faz ou continua na mesma" (08/03/2018).

Percebe-se, nas publicações, a exibição de corpos de pessoas magras e atléticas, que convidam seus seguidores a fazerem igual para alcançarem a "\#beleza", a "\#barrigachapada", a "\#boaforma", o "\#corpoperfeito", mas também a "\#qualidadedevida" e a "\#saúde". Muitas vezes, as categorias parecem intrínsecas umas às outras.

Além disso, destacam-se, nas escritas, indícios da tendência que Sant'Anna (2014) denomina de "hipersaúde", referente à crescente necessidade, expressa no sistema de formação discursiva sobre saúde, de se estar 100\% saudável, "sarado". Possivelmente, no Instagram, isso se reconfigure para a necessidade de dizer, ou de parecer estar, $100 \%$ saudável.

Ainda outras publicações reproduzem enunciados típicos de discursos de responsabilização dos sujeitos. Em determinada publicação, cuja ilustração traz uma mulher despindo-se da gordura (03/03/2018), o usuário é convidado a um "desafio" que consiste em "beber 2 l de água por dia, [ficar] sem frituras, sem refrigerante, sem açúcar, sem feijão e sem arroz na janta". Em outra publicação, observa-se uma selfie tirada após o treino junto à descrição: "Se você quer chegar ao lugar aonde a maioria não chega, deve fazer o que a maioria não faz. Quem desiste da luta, senta para assistir a vitória dos outros" (21/03/2018).

Encontra-se também nas publicações analisadas a presença de discursos prescritivos, estratégias dos sistemas de formação discursiva do contexto biopolítico, referentes aos procedimentos médicos de inoculação da população (FOUCAULT, 2008a).

Nesse sentido, salientam-se três publicações: na primeira o usuário dá o passo a passo para realizar o exercício de supino inclinado (21/03/2018); em uma segunda são exibidas dicas para obtenção de resultados mais rápidos, referente à frequência de treinamento, treinamento para perda de gordura abdominal, treinamento para mulheres e crianças (22/02/2018); e uma terceira, em que a imagem de uma mulher praticando exercícios é exibida, juntamente à seguinte descrição,"12 dicas para perder peso", com recomendações de comportamento como "mexa-se" e "Não coma por impulso" e de alimentação saudável, como "Capriche nas hortaliças" e "Pela manhã prefira ovos ao invés de pão" (15/03/2018).

Os enunciados, seja pelo texto interpelativo, seja pelas fotos de corpos magros, lisos e delineados, apresentam-se como vetores de uma subjetividade desejante. Isso pode ser percebido em outras duas publicações. Em uma, uma 
mulher muito magra, de cintura extremamente fina, aparece exibindo seu corpo de biquíni na praia, olhando para sua barriga; em outra, uma mulher bastante musculosa aparece tirando uma selfie em frente a um espelho, exibindo em especial a musculatura definida de sua barriga. Ambas com a mesma descrição feita apenas em hashtags: "\#musculação \#musculaçaomulheres \#musculacaomulheres \#nutrição \#saúde \#alimentação \#alimentacaosaudavel \#mulheres \#musculacaoparamulheres \#instafit \#academia \#treino \#dicas \#dicasfitness \#emagrecimento \#boaforma \#corpo \#atividadefisica \#comidadeverdade \#exercício \#sucesso \#foco \#meta \#crossfit \#agua \#top10 \#calorias \#qualidadedevida" (03/03/2018; 09/03/2018).

Apesar de não haver uma padronização acerca de determinado conceito de saúde nas publicações analisadas, percebe-se a predominância de enunciados referentes à responsabilização, reduzindo-a, tão somente, às escolhas individuais do sujeito para alcançar o "\#corpoperfeito" desejado e a "\#boaformafisica", a partir de uma "\#atitude" para um "\#estilodevida" com "\#saúdeintegral".

Ainda que algumas publicações ressaltem as singularidades de cada indivíduo, não deixam de produzir desejos e incutir responsabilidades. Por exemplo, uma usuária salienta "Não se baseie em outros corpos, faça do seu próprio corpo sua melhor versão!" (07/03/2018) e, no entanto, exibe uma imagem de uma jovem magra, usando uma roupa justa, que acentua sua cintura, em posição de equilíbrio, modelo contemporâneo de um ideário de saúde. Outra usuária, ao apresentar sua perspectiva de "\#terapia" a partir da "\#fisicaquantica", pergunta: "O que você pode escolher diferente que criaria uma nova realidade?" (23/02/2018). Os recursos são variados, basta escolher e buscar sua "melhor versão".

No entanto, em algumas publicações, parece que a saúde se vincula a outras perspectivas. Por exemplo, uma usuária mostra a página de um livro: "Sinto que precisamos, urgentemente, lembrar que a nossa humanidade é um exercício diário próprio da vida, e que abdicar dele, ou esquecê-lo, traz consequências graves, tanto para a nossa individualidade como para nossa sociedade". Como legenda, complementando sua perspectiva, a usuária ainda utiliza as hashtags "\#espiritualidade", "\#emoções", "\#sensações", "\#xamanismo", "\#terapiaholistica" e "\#meditacaoativa" (13/03/2018).

Outra usuária posta uma foto de si em posição de meditação e escreve: "Qual é o nome da sua doença? Qual rótulo foi colocado a ela? Quer seja pela ciência alternativa ou ciência fisiológica, entenda, SEMPRE o adoecer é um processo onde o ser humano não se adapta ao meio em que está vivendo" (07/03/2018). Mais uma usuária posta a seguinte mensagem em conjunto a hashtags como "\#espiritualidade", "\#bemestar" e "\#empatia": "Moça, ele não vai mudar por sua causa!... Ninguém muda por ninguém! O problema não está em você...” (25/03/2018).

Apesar de no corpus analisado predominarem discursos que se pautam por um conceito de saúde legitimado nas verdades científicas biomédicas, instituídas na sociedade ocidental, também se identificaram discursos que escapam a essa lógica. Isso assinala a emergência de outros saberes e outras verdades acerca do campo da saúde na atualidade. 
Considerando as características específicas da Internet, de replicabilidade, buscabilidade, escalabilidade e visibilidade (RECUERO; BASTOS; ZAGO, 2015), difunde-se a possibilidade de produção de discursos sobre saúde. Acessíveis rapidamente pelas hashtags - hiperlinks que levam aos hipertextos na rede -, as publicações no Instagram projetam-se a um nível macro.

Constroem-se novos saberes sobre saúde, potencialmente produtores de outros regimes de verdade, os quais implicam novos efeitos de realidade, relações de força e possibilidades de resistência. Assim, a produção de saberes vinculados à saúde na Internet torna-se exponencialmente difusa entre os usuários da rede.

\section{CONSIDERAÇÕES FINAIS}

Diante de todo o exposto neste trabalho, assinala-se que, no século $\mathrm{XXI}$, as redes sociais, na Internet, consolidam-se como parte operante das estratégias de governamentalidade. É nas redes sociais que se evidencia como se operacionaliza uma sociedade de controle na contemporaneidade, em que as relações de poder constroem engrenagens reais-virtuais-reais. Assim como na sociedade disciplinar, elas produzem um (bio)poder; agora, porém, virtualmente diluído.

As relações de poder produzidas difundem-se no corpo social e multiplicamse de forma rizomática, diluindo as fronteiras dos antigos espaços institucionais disciplinares. Fazer viver já não é mais tanto uma questão de confinamento, mas de controle sobre o corpo, sobre a saúde e a vida de cada um e, se possível, de todos. Esse controle constrói-se sobre a produção de verdades, subjetividades e desejos, processo relacionado - se não condicionado - a uma (bio)tecnologia, que permeia a zona de subjetivação enquanto delineia os contornos do diagrama ${ }^{14}$ de uma pósmodernidade.

O governo de si e dos outros, cada vez mais, opera-se em rede. No ciberespaço, as redes mostram os indícios das atuais estratégias de vigilância, que potencializam a produção de saberes sobre os sujeitos a partir de sua própria vontade em se mostrar, em explicitar cada vez mais suas subjetividades: condições essenciais para elaboração das estratégias de controle (COSTA, 2004).

Como apontado na análise deste trabalho, circulam, no Instagram, enunciados vinculados a práticas de confissão, intervenção e manipulação do corpo, relações entre corpo, saúde e beleza, estratégias de manutenção da saúde e normalização dos sujeitos, prescrição, responsabilização e criação de desejos. Na plataforma, os indivíduos buscam controlar uns aos outros e a si mesmos. Disseminam-se as relações de poder, mas também as estratégias de controle e de vigilância (COSTA, 2004).

Nesse sentido, o governo dos vivos na sociedade de controle, similar ao que apontou Foucault (2011) na sociedade disciplinar, se exerce na produção de verdades. Mudam-se, no entanto, as estratégias de produção e seus meios de disseminação, agora dissolvidos em relações rizomáticas de saber-poder.

14 Refere-se aqui à ilustração de Deleuze (2005, p.128) sobre o diagrama de Foucault. 
Isso não significa discutir se as publicações analisadas e os saberes que veiculam, a partir dos sistemas de formações discursivas em que se apoiam, são ou não verdadeiros. Afinal, para Foucault (2011), a verdade é, ela mesma, uma construção tensionada a partir das relações de poder. Nesse caso, "[...] importa menos a formação especializada de membros individuais. A credibilidade e relevância dos materiais publicados é reconhecida a partir da constante dinâmica de construção e atualização coletiva" (PRIMO, 2007, p. 4).

No modelo de sociedade de controle, operacionaliza-se um processo coletivo real-virtual de autoprodução e autovigilância pelas regras da evidência. Nas redes sociais, na Internet, os enunciados se disseminam a partir das relações estabelecidas entre os usuários acerca de "[...] quais informações serão reproduzidas, quais serão reverberadas, quais receberão visibilidade e quais serão debatidas [...]" (RECUERO; BASTOS; ZAGO, 2015, p. 132).

Alguns enunciados sobre saúde transpassam outros sistemas de formações discursivas, que não apenas aqueles vinculados às Ciências Médicas e Biológicas. Mesmo que se possa dizer que tais perspectivas não sejam predominantes, sua existência tensiona as relações de saber-poder, evidenciando que este espaço de produção de verdades não é neutro ou homogêneo. Como salienta Foucault (2016, p. 360), a resistência é coextensiva ao poder e "para resistir, é preciso que a resistência seja como o poder. Tão inventiva, tão móvel, tão produtiva quanto ele".

No contexto da sociedade de controle e das redes sociais na Internet, as condições de possibilidade de resistência adquirem configurações diferenciadas. No entanto, considerando que ainda a governamentalidade pareça ser exercida a partir da produção de verdades sobre os sujeitos, talvez o importante "[...] venha a ser criar vacúolos de não-comunicação, interruptores, para escapar ao controle" (DELEUZE, 1992, p. 217).

Como perspectivas futuras, a investigação das estratégias enunciativas em publicações de caráter comercial, bem como das relações de interação entre os sujeitos nas redes sociais na Internet, parece um caminho produtivo para novos estudos que tratem de temas emergentes no campo da saúde, fazendo interface com as questões de governamentalidade, na busca por mais indícios da operacionalização de uma sociedade de controle.

\section{REFERÊNCIAS}

ALVES, Marcelo. Abordagens da coleta de dados nas mídias sociais In: SILVA, Tarcízio; STABILE, Max (org.). Monitoramento e Pesquisa em Mídias Sociais: metodologias, aplicações e inovações. São Paulo: Editora Uva Limão, 2016. p. 67-84.

ANDRADE, Sandra dos Santos. Saúde e beleza do corpo feminino: Algumas representações no Brasil do Século XX. Movimento, v. 9, n. 1, p. 119-143, jan./abr. 2003.

ANTOUN, Henrique. As transformações da participação na sociedade hiperconectada. In: ANTOUN, Henrique (org.). Web 2.0: Participação e vigilância na era da comunicação distribuída. Rio de Janeiro: Mauad X, 2008. p. 7-9. 
CANGUILHEM, Georges. O Normal e o Patológico. Rio de Janeiro: Forense Universitária, 2010.

COSTA, Rogério da. Sociedade de Controle. São Paulo em Perspectiva, v. 18, n. 1, p. 6167, jan./mar. 2004.

DELEUZE, Gilles. Conversações: 1972-1990. Rio de Janeiro: Editora 34, 1992.

DELEUZE, Gilles. Foucault. São Paulo: Editora Brasiliense, 2005.

FERNANDES, Ana Carolina Machado. Eu sou o que como: As Musas do Instafit e a adoção de novos hábitos alimentares para a construção do corpo sarado. In: ENCONTRO NACIONAL DE ESTUDOS DO CONSUMO, 8.; ENCONTRO LUSO-BRASILEIRO DE ESTUDOS DO CONSUMO, 4.; ENCONTRO LATINO-AMERICANO DE ESTUDOS DO CONSUMO COMIDA E ALIMENTAÇÃO NA SOCIEDADE CONTEMPORÂNEA, 2., 2016, Niterói. Anais [...] Niterói, 2016, p. 1- 18. Disponível em: https://estudosdoconsumo.com/wpcontent/uploads/2018/11/ENEC2016-GT07-Fernandes-EuSouOQueComo.pdf. Acesso em: 16 jun 2020.

FOUCAULT, Michel. A ordem do discurso: aula inaugural no Collège de France, pronunciada em 2 de dezembro de 1970. São Paulo: Edições Loyola, 1996.

FOUCAULT, Michel. As Palavras e as Coisas. 8. ed. São Paulo: Martins Fontes, 1999b.

FOUCAULT, Michel. Ditos e Escritos IV: estratégia, poder-saber. 2 ed. Rio de Janeiro: Forense Universitária, 2006.

FOUCAULT, Michel. Do governo dos vivos: Curso no Collège de France, 1979-1980 (aulas de 09 e 30 de janeiro de 1980) São Paulo: Centro de Cultura Social, 2011.

FOUCAULT, Michel. Em defesa da sociedade: curso no Collège de France (1975 - 1976). São Paulo: Martins Fontes, 1999a.

FOUCAULT, Michel. Microfísica do Poder. 4. ed. Rio de Janeiro: Graal, 2016.

FOUCAULT, Michel. Nascimento da biopolítica: curso dado no Collège de France (19781979). São Paulo: Martins Fontes, 2008b.

FOUCAULT, Michel. Segurança, Território e População: curso no Collège de France (1977 - 1978). São Paulo: Martins Fontes, 2008a.

FOUCAULT, Michel. Vigiar e Punir. 33. ed. Petrópolis: Vozes, 2007.

FRAGA, Alex Branco. Exercício da informação: governo dos corpos no mercado da vida ativa. Campinas: Autores Associados, 2006.

GOMES, Isabelle Sena; CAMINHA, Iraquitan de Oliveira. Os discursos de corpo bem dito, mal dito e não dito: uma análise a partir de filmes. Revista Brasileira de Ciências do Esporte, v. 38, n.4, p. 414-421, 2016.

HARDT, Michael. A sociedade mundial de controle. In: ALLIEZ, Eric (org.). Gilles Deleuze: uma vida filosófica. São Paulo: Editora 34, 2000. p. 357-72.

JACOB, Helena. Redes sociais, mulheres e corpo: um estudo da linguagem fitness na rede social Instagram. Revista Communicare - Dossiê Feminismo. v.14, n. 1, p. 88 - 105, 2014. 
LEITZKE, Angélica Teixeira da Silva; RIGO, Luiz Carlos; KNUTH, Alan Goularte. Estratégias biopolíticas de construção do corpo e vigilância da saúde: o caso "Medida Certa". Revista Brasileira de Ciências do Esporte, v. 42, e2014, 2020. DOI: https://doi.org/10.1016/j. rbce.2018.12.001.

LÉVY, Pierre. As tecnologias da inteligência: o futuro do pensamento na era da informática. São Paulo: Editora 34, 1993.

LÉVY, Pierre. Cibercultura. São Paulo: Editora 34, 1999.

OLIVEIRA, Alexandre Palma de; ASSIS, Monique; LACERDA, Yara; BAGRICHEVSKY, Marcos; SAMPAIO, Karen Santana de. Culto ao corpo e exposição de produtos na mídia especializada em estética e saúde. Movimento, v. 16, n. 01, p. 31-51, jan./mar. 2010.

O'REILLY, Tim. Design Patterns and Business Models for the Next Generation of Software, 2005. Disponível em: https://www.oreilly.com/pub/a/web2/archive/what-is-web-20. html. Acesso em: 13 jan. 2018.

PRIMO, Alex. Interação mútua e reativa: uma proposta de estudo. Revista da Famecos, n. 12, p. 81-92, jun. 2000.

PRIMO, Alex. O aspecto relacional das interações na Web 2.0. E-Compós v. 9, p. 1-21, 2007.

RECUERO, Raquel; BASTOS, Marco; ZAGO, Gabriela. Análise de redes para mídia social. Porto Alegre: Sulina, 2015.

SANT’ANNA, Denise Bernuzzi. História da Beleza no Brasil. São Paulo: Contexto, 2014.

SANTOLIN Cezar Barboza; RIGO, Luiz Carlos. O nascimento do discurso patologizante da obesidade. Movimento, v. 21, n. 1, p. 81-94, jan./mar. 2015.

SIBILIA, Paula. O show do eu: a intimidade como espetáculo. Rio de janeiro: Nova Fronteira, 2008.

SILVA, Thiago Henrique et al. Uma Fotografia do Instagram: Caracterização e Aplicação. In: SIMPÓSIO BRASILEIRO DE REDES DE COMPUTADORES E SISTEMAS DISTRIBUÍDOS, 2013, Brasília. Anais [...], 2013, p. 455-468. Disponível em: https://pdfs.semanticscholar.org/ a612/06e642cff1165d0a95e7ee0fc0c9d425aa93.pdf. Acesso em: 6 jun. 2020.

VIGARELLO, Georges. História da beleza: O corpo e a arte de se embelezar, do Renascimento aos dias de hoje. Rio de Janeiro: Ediouro, 2006. 
Abstract: This article aims to analyze text and images posted on Instagram under the hashtags \#saúde (Portuguese for health) and \#corpo (body), based on Deleuze's notion of society of control. Data were collected using the website Netlytic and analyzed with the software LibreOffice Calc. The methodology consisted of statement analysis from a Foucauldian perspective. The results stress the presence of practices addressing techniques of confession, intervention, and body manipulation as well as control strategies to promote health based on production of truth. These are indications of how today's health surveillance mechanisms and governmentality strategies are operationalized in the society of control.

Keywords: e-Government. Population Control. Health. Online Social Networking.

Resumen: Este artículo tiene como objetivo analizar texto e imagen de publicaciones en la red social Instagram, con las hashtags \#salud y \#cuerpo, a partir de la noción deleuzeana de sociedad de control. Para la recolección de datos, fue utilizado el sitio Netlytic, y, para la selección de los datos, el software LibreOffice Calc. La metodología consiste en un análisis enunciativo de perspectiva foucaultiana. Los resultados apuntan a la presencia de prácticas que remiten a las técnicas de confesión, de intervención y de manipulación del cuerpo y a las estrategias de control para la producción de salud a partir de la producción de verdades. Esos son indicios de la operacionalización de los actuales mecanismos de vigilancia de la salud y de las estrategias de gubernamentalidad en la sociedad de control.

Palabras clave: Gobierno electrónico. Regulación de la población. Salud. Redes sociales on-line. 


\section{LICENÇA DE USO}

Este é um artigo publicado em acesso aberto (Open Access) sob a licença Creative Commons atribuição Não Comercial 4.0 (CC BY-NC 4.0), que permite uso, distribuição e reprodução em qualquer meio, desde que o trabalho original seja corretamente citado, com a restrição que impede o uso para fins comerciais. Mais informações em: http://creativecommons.org/licenses/by-nc/4.0

\section{CONFLITO DE INTERESSES}

Os autores declararam que não há conflito de interesses neste trabalho.

\section{CONTRIBUIÇÕES AUTORAIS}

Angélica Teixeira da Silva Leitzke: Coleta e análise de dados. Redação e revisão de texto.

Luiz Carlos Rigo: Análise de dados. Redação e revisão de texto.

\section{FINANCIAMENTO}

O presente estudo foi desenvolvido integralmente sob as expensas dos pesquisadores. Não houve, portanto, nenhuma forma de financiamento externa.

\section{ÉTICA EM PESQUISA}

Os autores declaram que a coleta seguiu a Política de dados do Instagram, disponível em: https://help.instagram.com/519522125107875 e observou as recomendações do Comitê de Trabalho de Ética da Association of Internet Researchers (AoIR), disponivel em: https://aoir.org/ethics/

\section{COMO REFERENCIAR}

LEITZKE, Angélica Teixeira da Silva; RIGO, Luiz Carlos. Sociedade de controle e redes sociais na internet: \#saúde e \#corpo no instagram. Movimento, v. 26, e26062, jan./dez. 2020. Disponível em: https://seer.ufrgs.br/Movimento/article/ view/100688. Acessado em: 20 ago. 2020. DOI: https://doi.org/10.22456/1982$\underline{8918.100688}$

\section{RESPONSÁVEIS EDITORIAIS}

Alex Branco Fraga*, Elisandro Schultz Wittizorecki*, Ivone Job*, Mauro Myskiw*, Raquel da Silveira*

*Universidade Federal do Rio Grande do Sul, Escola de Educação Física, Fisioterapia e Dança, Porto Alegre, RS, Brasil 